Dietmar Kammerer (Hg.)

Vom Publicum

Image | Band I9 

Dietmar Kammerer (HG.)

\section{Vom Publicum}

Das Öffentliche in der Kunst 
Die Publikation wurde gefördert durch die DFG und

das Internationale Graduiertenkolleg »InterArt«.

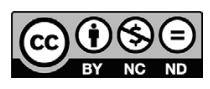

Dieses Werk ist lizenziert unter der

Creative Commons Attribution-NonCommercial-NoDerivs 3.0 (BY-NC-ND).

Diese Lizenz erlaubt die private Nutzung, gestattet aber keine Bearbeitung und keine kommerzielle Nutzung. Weitere Informationen finden Sie unter

https://creativecommons.org/licenses/by-nc-nd/3.o/de/.

Die Deutsche Nationalbibliothek verzeichnet diese Publikation in der Deutschen Nationalbibliografie; detaillierte bibliografische Daten sind im Internet über http://dnb.d-nb.de abrufbar.

\section{() 2012 transcript Verlag, Bielefeld}

Die Verwertung der Texte und Bilder ist ohne Zustimmung des Verlages urheberrechtswidrig und strafbar. Das gilt auch für Vervielfältigungen, Übersetzungen, Mikroverfilmungen und für die Verarbeitung mit elektronischen Systemen.

Umschlaggestaltung: Kordula Röckenhaus, Bielefeld;

unter Verwendung einer Abbildung von Getty Images

Lektorat \& Satz: Dietmar Kammerer

Druck: Majuskel Medienproduktion $\mathrm{GmbH}$, Wetzlar

Print-ISBN 978-3-8376-1673-6

PDF-ISBN 978-3-8394-I673-6

Gedruckt auf alterungsbeständigem Papier mit chlorfrei gebleichtem Zellstoff.

Besuchen Sie uns im Internet: $h t t p: / / w w w . t r a n s c r i p t-v e r l a g . d e$

Bitte fordern Sie unser Gesamtverzeichnis und andere Broschüren an unter: info@transcript-verlag.de 